\title{
Social Network Analysis of Stakeholder Relationships during Construction Industrialization in China
}

\author{
Yingbo $\mathrm{JI}^{1 *}$, Xiaotong $\mathrm{LI}^{1}$, Hong Xian $\mathrm{LI}^{2}$, Shiguo Sun ${ }^{1}$, Mohamed Al-HUSSEIN ${ }^{2}$, and Limao \\ $\mathrm{ZHANG}^{2}$ \\ ${ }^{1}$ School of Civil Engineering, North China University of Technology, Beijing, China, 100041 \\ ${ }^{2}$ Hole School of Construction Engineering, Department of Civil and Environmental Engineering, \\ University of Alberta, 9105 116th St. NW, Edmonton, Canada, T6G 2W2 \\ ${ }^{*}$ Corresponding author's e-mail: yingboji@126.com
}

\begin{abstract}
Modular and off-site construction has garnered world-wide attention, as evidenced by the gathering momentum of construction industrialization in China. This entails a transition for stakeholders within the construction industry, as construction industrialization will alter relationships among stakeholders on a number of levels. In this research, the stakeholders involved in construction industrialization in China are identified, and the stakeholder relationships are quantified through three surveys. Based on the collected data, the stakeholder relationships are mapped and analyzed using social network analysis. The results indicate that the social network of industrialization construction is not dense and less tied, generates relatively low impacts on the behaviors of individual stakeholders; as the most influential stakeholders, the general contractor, owner, and surveyors and designers control most of the resources; due to their influence in the form of policies, the government can become an important stakeholder during the process of construction industrialization Through strengthening the policy guidance, it can attract new stakeholders for the integrated network, incubate a construction industrialization corporate group with integrated abilities of $\mathrm{R} \& \mathrm{D}$, design, construction and operation, which is valuable to effectively promote the development of construction industrialization in China.
\end{abstract}

\section{KEYWORDS}

Construction Industrialization, Social Network Analysis, Stakeholder Analysis

\section{INTRODUCTION}

The construction industry in China has been growing at a tremendous rate in recent years. From 2003 to 2014, revenue has increased from 750 billion yuan to approximately 17,670 billion yuan, with an annual growth rate of $30.12 \%$. Currently, the annual completed floor area of buildings in China exceeds 4.2 billion $\mathrm{m}^{2}$. An industrial chain has formed encompassing many different facets including building materials, real estate, operation and maintenance, and engineering construction; the construction industry has become the nation's highest economic contributor among industrial sectors. However, the construction industry in China is encountering such challenges as rapid development, insufficient technologies, enormous consumption of resources, massive waste, compromised quality, safety risks, low productivity, and a shortage of skilled labour (Ji 2011). These problems are restricting the sustainable development of the industry in China; therefore, innovative technologies are needed to reform the construction industry. Industrialization of the construction process is a solution to mitigate these challenges. 
Construction industrialization is defined as factory-based prefabrication within a controlled environment, followed by assembly on site. When compared to conventional construction methods, benefits of industrialized construction include accelerated construction, improved quality, decreased material waste, and reduced hazards and worker injuries ( $\mathrm{Li}$ et al. 2014). It also contributes to sustainability by substantially reducing energy usage and thus reducing greenhouse gas emissions from the construction process. Construction industrialization has gained much attention and support from the government at the national, provincial, and municipal levels in China. In recent years, the government has successfully issued favourable policies to encourage construction industrialization. The use of industrialized construction methods is mandatory for affordable housing and public buildings in some jurisdictions, and it is expected that the total floor area built by means of industrialized construction in China will exceed 40 million $\mathrm{m}^{2}$ by 2017 ( $\mathrm{Ji}$ and Li 2014).

Construction industrialization involves multiple stakeholders: government, surveyors and designers, contractors, sub-contractors, trades and suppliers, owners, prefabrication manufacturers, and consultants. This group of stakeholders forms new social networks and relationships (Powell et al. 1996; Kapsali 2011; Girmscheid and Rinas 2012). Any type of social relationship will have positive or negative influence on the behaviour of other stakeholders. Social network analysis provides an effective tool for studying interactions among organizations and exploring rules concealed under complicated social systems (Uzzi 1997; Hu and Rachera 2008; Nayak et al. 2009). During the development process of construction industrialization, social network analysis can effectively uncover the attributes of the relationship network, as well as the mutual influence on behavioural strategies (Rowley 1997; Troshani and Doolin 2007; Mukherjee and Muga 2009). The results of social network analysis of stakeholders can advance the development of construction industrialization in China.

Research on social network has been conducted within the construction domain. Early studies primarily focused on the industrial network issues at the interpersonal level in specific conditions, including bidding competitions, crisis conditions, and information exchanges (Soda and Usai 1995; Loosemore 1998; Pryke 2004). More recent research applying social network theory to construction has placed the focus more on organizations and project governance (Chinowsky et al. 2008; Boddy et al. 2009; Hartmann and Fischer 2009; Wong et al. 2010). This research will investigate and analyze the stakeholder network of construction industrialization in China, using social network analysis as the approach; this research aims to investigate the underlying mechanism of stakeholder relationships and to provide recommendations for effectively promoting the performance and capacity of construction industrialization in China.

\section{RESEARCH OBJECTIVE AND METHODOLOGY}

This research aims to investigate the relationships among stakeholders in construction industrialization in China. The research objectives include: (1) to quantify stakeholder relationships; (2) to analyze stakeholder relationships; and (3) to provide suggestions for the betterment of the construction industrialization process. The inputs of the methodology include industrialized construction cases and stakeholder opinions about stakeholder relationships. First, the stakeholders in industrialized construction in China are identified; the identified stakeholders are surveyed about the nature of the stakeholder relationships. Each stakeholder relationship is quantified using a scale from one to five, which incorporates matrices of communication, 
reliability, trust, and commitment. The survey results are quantified to build a social network for construction industrialization. The measurement indices for the whole network as well as for individual stakeholders are analyzed, based on which suggestions for industrialized construction in China are proposed. Social network theory, UCINET software, and policy framework comprise the research constraints. The research framework is demonstrated in Figure 1.

Main Process

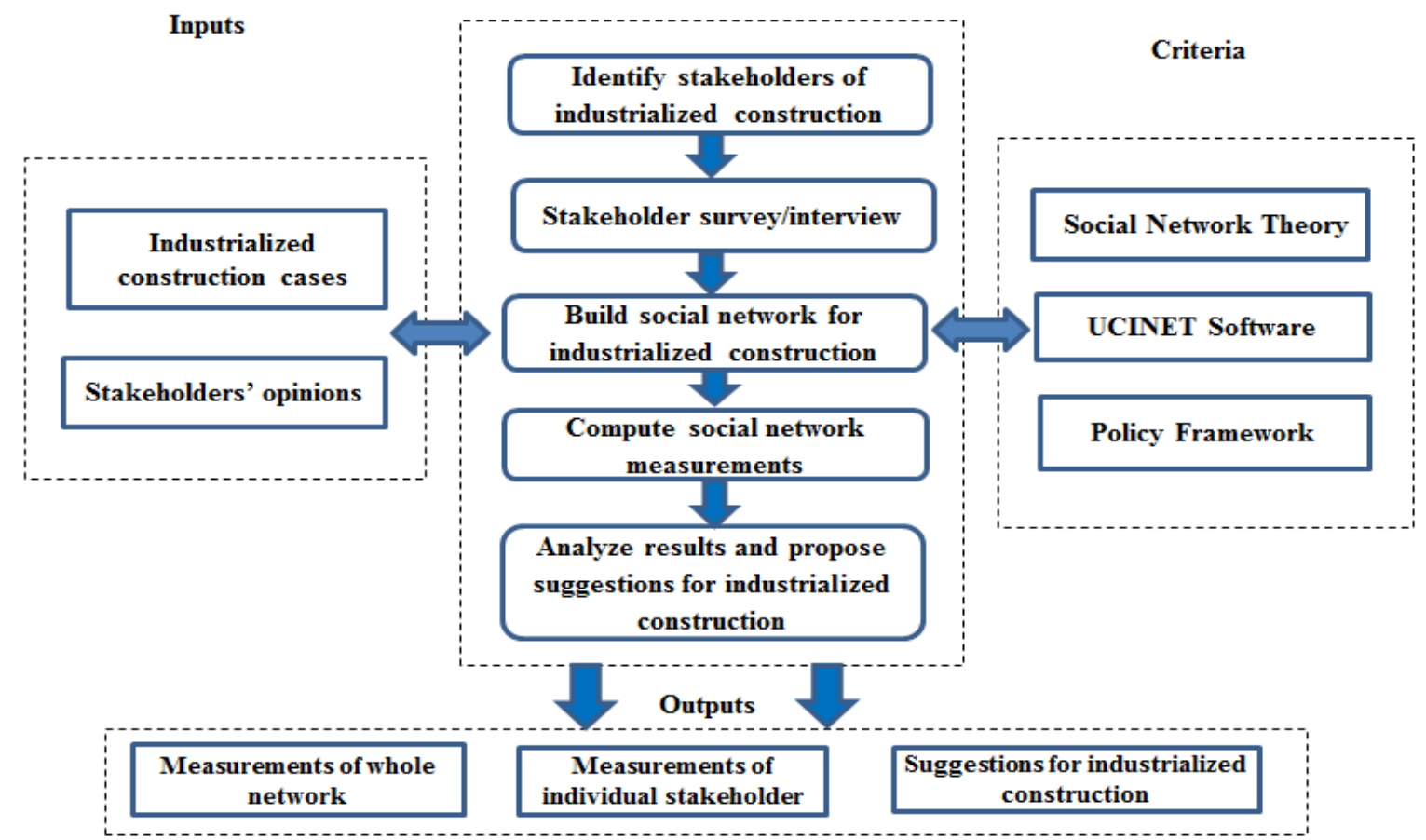

Figure 1. Research methodology

There exist two sets of measurements corresponding to the whole network and to individual stakeholders, respectively.

(1) Whole network measurement: Such indices as density and centralization are used to assess the whole social network. Density is used to measure the cohesion of the entire network; a higher density means that more ties exist among stakeholders. Centralization is calculated to quantify the domination of individuals; the higher the value, the more the network is dominated by those individuals. The equations used to calculate density and centralization are listed as Equation (1) and Equation (2).

$$
D=\frac{l}{n(n-1) / 2}=\frac{2 l}{n(n-1)}
$$

Where: $D$ is network density; $n$ is number of nodes, with maximal $n(n-1) / 2$ edges in a network of $n$ nodes; $l$ is number of actual edges.

$$
C=\frac{\sum_{1}^{n}\left(C_{\max }-C_{i}\right)}{\max \left[\sum_{1}^{n}\left(C_{\max }-C_{i}\right)\right]}
$$


Where: $C$ is network centralization; $C_{\max }$ is maximal centralization of network nodes; $C_{\mathrm{i}}$ is the centralization of node $i$, other than $C_{\max }$.

(2) Individual measurement: Three indices-degree centrality, betweenness centrality, and closeness centrality-are used to assess individual stakeholders. Degree centrality is used to measure the ties of an individual with others; a high degree of centrality means an individual has more connections with others, and has more influence on other stakeholders. Betweenness centrality measures how often a stakeholder appears between two other stakeholders, and can be interpreted as the potential controller of the flows through the network. Closeness centrality of a node is the sum of geodesic distances to all other nodes in a network, measuring the extent to which a node is reached by other nodes. More specifically, the closeness is further assessed with directions of nodes, in terms of InCloseness and OutCloseness. InCloseness measures the impact of the internal part of the node on the external environment; while OutCloseness measures the impact of the external environment on the internal part of the node. A small value of closeness centrality means a node is more reachable by other nodes (Wasserman and Faust 1997; Kim 2007; de Nooy et al. 2005). The equations used to calculate the three measurements mentioned above are listed as Equations (3), (4), and (5).

$$
C_{D}\left(n_{i}\right)=\frac{\sum_{1}^{j} e_{i, j}}{n-1}
$$

Where: $C_{D}\left(n_{i}\right)$ is degree centrality of node; $j$ is number of nodes, which are connected with node $n_{\mathrm{i}} ; e_{i, j}$ is edge between $i$ and $j, n-1$ is maximal edges of n nodes.

$$
C_{B}\left(n_{i}\right)=\sum_{j<k} \frac{g_{j k}\left(n_{i}\right)}{g_{j k}}
$$

Where: $C_{B}\left(n_{i}\right)$ is betweenness centrality of node; $g_{j k}\left(n_{i}\right)$ is number of geodesic paths (i.e., shortest paths) that pass through a node $n_{\mathrm{i}} ; g_{j k}$ is number of geodesic paths between nodes.

$$
C_{C}\left(n_{i}\right)=\frac{n-1}{\sum_{j}^{n} d\left(n_{i}, n_{j}\right)}
$$

Where: $C_{c}\left(n_{i}\right)$ is closeness centrality of node; $d\left(n_{i}, n_{j}\right)$ is geodesic distances between nodes; $n$ is number of nodes in a network.

\section{CASE STUDY}

\section{Social network of construction industrialization}

Numerous demands exist on affordable housing in the current Chinese housing market, which provide valuable opportunities for industrialization of construction. Two public rental buildings and one affordable housing building, all built using industrialized construction methods, are selected as the case examples in this research. The identified stakeholders include project owners, surveyors and designers, general contractors, sub-contractors, prefab manufacturers, third-party construction supervisors, trades and suppliers, government agencies, researchers, consultants, and financial institutions. The survey samplings are demonstrated in Table 1. Based on the survey results, the social network is built using UCINET as a tool, which is depicted in Figure 2. The calculated results are recorded in Table 2. 
Table 1 Questionnaire Samples

\begin{tabular}{c|c|c|c|c|c|c}
\hline \multirow{2}{*}{ Projects } & \multicolumn{2}{|c|}{ Project A } & \multicolumn{2}{c|}{ Project B } & \multicolumn{2}{c}{ Project C } \\
\hline \multirow{2}{*}{ Samples } & Hard Copy & E-mail & Hard Copy & E-mail & Hard Copy & E-mail \\
\cline { 2 - 7 } & 20 & 46 & 12 & 30 & 12 & 65 \\
\hline
\end{tabular}

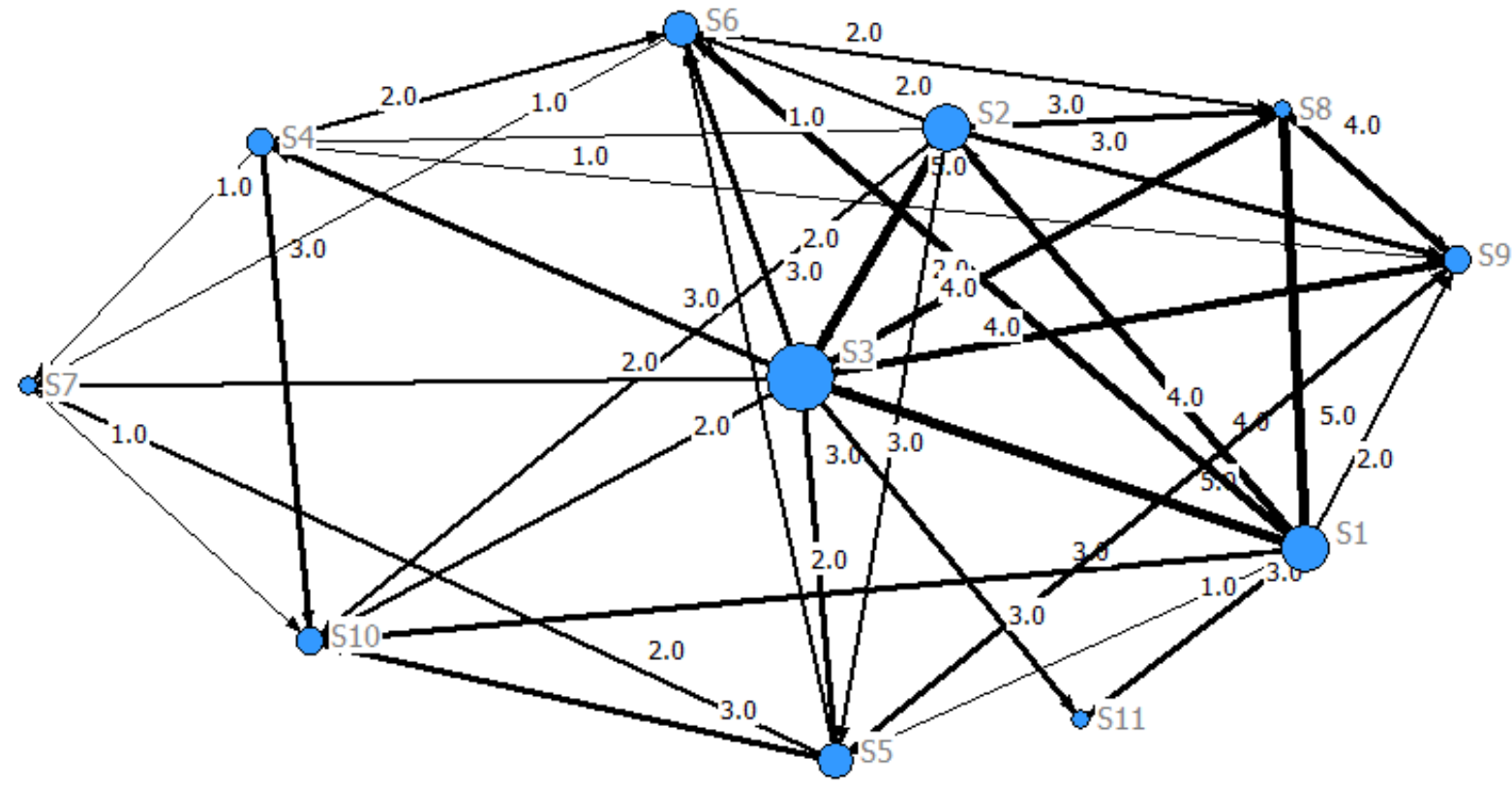

Figure 2. Stakeholder relationship network

\section{Results and analysis}

\section{(1) Whole network analysis}

Using Equation (1), the network density is calculated to be $27.67 \%$, which is approaching zero, instead of one. The results indicate that the social network of industrialization construction is not dense and less tied, and the construction industrialization network generates relatively low impacts on the behaviors of individual stakeholders. In other words, a well-organized and mature construction industrialization market has not developed.

The centralization of the network is calculated to be $19.40 \%$, which indicates the existence of resource controllers in this network. This calculated proportion means that $19.40 \%$ of individual stakeholders can manage the resources in the construction industrialization market in an effective manner. As we can see, the rest of the stakeholders $(80.60 \%)$ cannot use the market resources effectively, which demonstrates that the degree of the construction industrialization clustering is not high. Thus, the reasonable distribution of the power and resources among individual stakeholders should be the direction of future development in the construction industrialization process. 


\section{(2) Individual stakeholder analysis}

In regards to degree centrality, the general contractor is ranked highest, with $68 \%$ degree centrality, which means the general contractor has the most connections with other stakeholders, and that the general contractor is the most influential stakeholder. The second-most influential stakeholder is the project owner, with $54 \%$ degree centrality, and the third is surveyors and designers, while government agencies are ranked fourth. The degree centrality results reflect the fact that the government has certain influence on the industrialized construction process, and that the industry also plays a central role.

In terms of betweenness centrality, the general contractor is ranked highest, with $2.583 \%$ betweenness centrality, which means the general contractor is the main network controller. The owner is second, while surveyors and designers is third, and government agencies are fourth. The other stakeholders have very low betweenness centrality. The measurement of betweenness centrality implies that most of the resources are controlled by the general contractor, the owner, surveyors and designers, and government agencies, where other stakeholders have very little control of resources.

With respect to closeness centrality, the consultants and researchers have higher outCloseness and lower inCloseness, which means both depend on other stakeholders for resources. However, both consultants and researchers can access other stakeholders easily, which makes both stakeholders main contributors to the transmission of knowledge and technology. The general contractor and owner have lower outCloseness and higher inCloseness, which means they are lacking in terms of access to other stakeholders.

Table 2 Centrality of individual stakeholders

\begin{tabular}{lcccc}
\hline \multirow{2}{*}{ Stakeholder } & $\begin{array}{c}\text { Degree } \\
\text { Centrality }\end{array}$ & $\begin{array}{c}\text { Betweenness } \\
\text { Centrality }\end{array}$ & \multicolumn{2}{c}{ Closeness Centrality } \\
\cline { 4 - 5 } & inCloseness & outCloseness \\
\hline Project Owners & 54.000 & 2.083 & 10.000 & 45.455 \\
\hline $\begin{array}{l}\text { Surveyors and } \\
\text { designers }\end{array}$ & 44.000 & 1.648 & 11.111 & 33.333 \\
\hline General contractors & 68.000 & 2.583 & 9.091 & 83.333 \\
\hline Sub-contractors & 22.000 & 0.500 & 12.346 & 16.393 \\
\hline $\begin{array}{l}\text { Prefab manufacturers } \\
\text { Third-party }\end{array}$ & 31.000 & 0.519 & 12.500 & 16.393 \\
\hline $\begin{array}{l}\text { construction } \\
\text { supervisors }\end{array}$ & 32.000 & 0.250 & 16.667 & 13.889 \\
\hline Trades and suppliers & 14.000 & 0.000 & 19.231 & 10.000 \\
\hline \begin{tabular}{l} 
Government agencies \\
\hline
\end{tabular} & 36.000 & 1.000 & 19.231 & 10.000 \\
\hline
\end{tabular}




\begin{tabular}{lllll}
\hline Researchers & 34.000 & 0.000 & 24.390 & 9.091 \\
\hline Consultants & 14.000 & 0.000 & 24.390 & 9.091 \\
\hline Financial institutions & 12.000 & 0.583 & 12.346 & 9.091 \\
\hline
\end{tabular}

\section{CONCLUSIONS}

This research has investigated and analyzed the stakeholder relationships of construction industrialization in China. Based on the results and analysis mentioned, it can be concluded that: (1) the whole network of construction industrialization is sparse, and the ties that exist among the stakeholders are weak. To mitigate this situation, external stakeholders need to be attracted through various forms of cooperation, it can transform the sparse network into thick network of construction industrialization; (2) the general contractor, owner, and surveyors and designers are the most influential stakeholders, and control most of the resources. To ensure sustainable development of construction industrialization, the building manufacturer needs to be motivated through beneficial policies, among other factors. These stakeholders must enhance the industrial technologies, manages innovation activities, construct industry-university-research synergy innovation platforms, incubate and form a construction industrialization corporate group with integrated abilities of $\mathrm{R} \& \mathrm{D}$, design, construction and operation, and forms its unique competitive edge. Its core status in the network will also exert important impact on other stakeholders; (3) due to their influence in the form of policies, the government can become an important stakeholder during the process of construction industrialization and continue to provide sufficient support. Overall, the current social network functions well for the onset of construction industrialization in China; however, additional categories of stakeholders need to be incorporated into the process and the ties among the stakeholders need to be enhanced through government policies that incentivize industrialization of construction.

\section{ACKNOWLEDGEMENTS}

The authors are grateful for the support from the Natural Science Foundation of China Subject through the research project, "Research on collaborative innovation mechanism construction industrialization among stakeholders: Based on dynamic social network" (71401002), sponsorship from the Ministry of Science and Technology of People's Republic of China through the project, "Research on installation key technology and scale application demonstration" (2011BAJ10B06), and the Ministry of Science and Technology of People's Republic of China through the project, "Research on green building standards and different constructions' standards in different regions" (2012BAJ10B01).

\section{REFERENCES}

Boddy, S., Rezqui, Y., Cooper, G., and Wetherill, M. (2010). "Activity awareness as an enabler for communication and network building in construction design teams." Journal of Computing in Civil Engineering, 24(5), 430-440.

Chinowsky, P., Diekmann, J., and Galotti, V. (2008). "Social network model of construction." Journal of Construction Engineering Management, 134(10), 804-812.

De Nooy, W., Mrvar, A., and Batageli, V. (2005). "Exploratory social network analysis with Pajek." Cambridge University Press, Cambridge, UK.

Girmscheid, G., and Rinas, T. (2012). "Business Design Modeling for Industrialization in 
Construction: Cooperative Approach." Journal of Architectural Engineering, 18(2), 164-175.

$\mathrm{Hu}, \mathrm{C}$., and Rachera, P. (2008). "Visual representation of knowledge networks: a social network analysis of hospitality research domain." International Journal of Hospitality Management, 27, 302-312.

Ji, Y. (2011). "Construction Industrialization Development Research." China Architecture \& Building Press.

Ji, Y. and Li, X. (2014). "Policy Suggestions on the Development of Construction industrialization." Construction Enterprise Management, 5, 60-61.

Kapsali, M. (2011). "Systems thinking in innovation project management: A match that works." International Journal of Project Management, 29(4), 396-407.

Kim, Y. H. (2007). "Social network analysis." Parkyoungsa, Seoul, Korea.

Li, H. X., Esfahani, M. N., Gul, M., Yu, H., Mah, D. and Al-Hussein, M. (2014). "Carbon footprint of panelized construction: an empirical and comparative study." Proceedings of Construction Research Congress, ASCE, Atlanta, GA, 2014, May 21-23.

Loosemore, M. (1998). "Social network analysis using a quantitative tool within an interpretative context to explore the management of construction crises." Engineering Construction and Architectural Management, 5(4), 315-326.

Mukherjee, A., and Muga, H. (2009). "A Decision-Making Framework to Assess Stakeholder Value in Adoption of Sustainable Practices in Construction." Construction Research Congress Building a Sustainable Future, ASCE, 118(3), 548-557.

Nayak, N. V., and Taylor, J. E. (2009). "Offshore outsourcing in global design networks." Journal of Management in Engineering, 25(4), 177-184.

Powell, W. W., Koput, K. W., and Smith-Doerr, L. (1996). "Interorganizational collaboration and the locus of innovation: Networks of learning in biotechnology." Administrative science quarterly, (2), 116-145.

Pryke, S. D. (2004). "Analyzing construction project coalitions: Exploring the application of social network analysis." Construction Management and Economics, 22(8), 787-797.

Rowley, T J. (1997). "Moving beyond dyadic ties: A network theory of stakeholder influences." Academy of management Review, 22(4), 887-910.

Soda, G., and Usai, A. (1995). "Institutional embeddedness and interorganization-al networks in the Italian construction industry." Industry Structure and Interorganisational Networks Conf., Geneva, Switzerland.

Troshani, I., and Doolin, B. (2007). "Innovation diffusion: a stakeholder and social network view." Journal of Innovation Management, 10(2), 176-200.

Uzzi, B. (1997). "Social structure and competition in interfirm networks: The paradox of embeddedness." Administrative Science Quarterly, 5, 35-67.

Wasserman, S., and Faust, K. (1997). "Social network analysis: Methods and applications." Cambridge University Press, Cambridge, UK.

Wong, K., Unsal, H., Taylor, J. E., and Levitt, R. (2010). "Global dimension of robust project network design." Journal of Construction Engineering and Management, 136(4), 442-451. 